\title{
Petrologia e geoquímica das suítes intrusivas Vila Rica e Rio Dourado - Província Amazônia Central, borda sudeste do Cráton Amazônico (MT)
}

\author{
Rosilene Aparecida Padilha ${ }^{1}$ \& Márcia Aparecida de Sant'Ana Barros ${ }^{2}$
}

\begin{abstract}
Resumo A Suíte Intrusiva Vila Rica é composta de biotita-monzogranito e biotita-sienogranito com textura hipidiomórfica de granulação fina a média. Os teores de elementos maiores e traços sugerem afinidade cálcio-alcalina a cálcio alcalina de alto-K e caráter peraluminoso. Padrões de Elementos Terras Raras marcados pelo enriquecimento de leves sobre pesados e ausência de anomalia de Eu indicam origem a partir de magmas fracionados com participação de plagioclásio, clinopiroxênio e hornblenda. Teores de $\mathrm{Rb}$ versus $\mathrm{Y}+\mathrm{Nb}$ projetam os granitos desta suíte no campo de granitos pós-colisionais. A análise do diagrama multielementar normalizado pelos valores dos Granitos de Cadeias Oceânicas, caracteriza-se por apresentar anomalia negativa de $\mathrm{Nb}$ e Ta. A Suíte Intrusiva Rio Dourado é constituída de anfibólio-biotita-sienogranito, biotita-sienogranito e monzogranito. A petrografia associada aos dados geoquímicos indica afinidade alcalina e caráter metaluminoso a peraluminoso. O padrão de Elementos Terras Raras da Suíte Intrusiva Rio Dourado é caracterizado por um leve enriquecimento de leves sobre pesados e forte anomalia negativa de Eu indicando o fracionamento de plagioclásio durante a evolução do magma. Padrões de multi-elementos mostram anomalia negativa de $\mathrm{Nb}$ e Ta. Os resultados de elementos traços para estes granitos são similares aos de granitóides tipo A, sub-tipo A2 e indicam ambiente tectônico pós-colisional.
\end{abstract}

Palavras-chave: granitos paleoproterozóicos, Cráton Amazônico, Província Amazônia Central, granitos tipo-A.

\begin{abstract}
Petrology and geochemistry of the Vila Rica and Rio Dourado intrusive suites - Central Amazonian Province, southeastern edge of the Amazonian Craton (MT). The Vila Rica Intrusive Suite is composed of fine to medium grained hipidiomorphic biotite-monzogranite, biotite-syenogranite and quartz-syenite . The major and trace elements abundances suggest peraluminous and alkaline affinities. Rare Earth Elements patterns show-REE/HREE ratios. The lack of Eu anomaly suggests that plagioclase was not a fractionated phase during magmatic evolution. On the $\mathrm{Rb}$ versus $\mathrm{Y}+\mathrm{Nb}$ diagram the Vila Rica Intrusive Suite are classified as post-collisional granites. The spidergram normalized to the ocean ridge granite patterns shows negative $\mathrm{Nb}$ and $\mathrm{Ta}$ anomalies. The Rio Dourado Intrusive Suite is composed of amphibole-biotite-syenogranite, biotite-syenogranite and monzogranite, locally showing amphibole with hastingsite composition. The geochemical and petrographic data suggest alkaline,-metaluminous to peraluminous affinity. The REE patterns are characterized by slightly high LREE/HREE ratios and strong negative Eu anomalies which suggest plagioclase fractionation during magmatic evolution. Incompatible element distributions diagrams normalized to the ocean ridge granite values from Rio Dourado Intrusive Suite exhibit negative anomaly of $\mathrm{Nb}$ and $\mathrm{Ta}$. Traces elements values are similar to A-type, $\mathrm{A}_{2}$-sub type granites and suggest intrusion during post-collisonal tectonic setting.
\end{abstract}

Keywords: paleoproterozoic granites, Amazonian Craton, Central Amazonian Province, A- type granites.

INTRODUÇÃo A área estudada está localizada no nordeste de Mato Grosso, divisa com Tocantins e Pará. No Mato Grosso, a Província Amazônia Central (Cráton Amazônico) é quase totalmente desconhecida, o que torna de suma importância a ampliação de seu conhecimento geológico e geocronológico. Embora pequenas porções já tenham sido mapeadas em detalhe, na região estudada, este é o primeiro trabalho a ser publicado com o objetivo de caracterização petrográfica e geoquímica dos granitos das suítes intrusivas Vila Rica $(1970 \pm 9 \mathrm{Ma})$ e Rio Dourado $(1890 \pm 11 \mathrm{Ma})$.
CONTEXTO GEOLÓGICO REGIONAL As suítes intrusivas Vila Rica e Rio Dourado estão inseridas nos domínios da Província Amazônia Central. Esta província é a porção mais antiga do Cráton Amazônico e foi dividida em dois blocos (Tassinari \& Macambira 1999). O Roraima, a norte e Carajás-Iricoumé, ao sul. Os autores basearam essas divisões em dados geocronológicos e estruturais. O Bloco Carajás-Iricoumé foi subdividido em duas áreas: Carajás e Xingú-Iricoumé, sendo que a área Carajás representa a porção mais antiga do cráton amazônico, constituindo-se de terreno de

1 - Programa de Pós-Graduação em Geociências, Instituto de Ciências Exatas e da Terra, Universidade Federal de Mato Grosso, Cuiabá (MT), Brasil. E-mail: rosilene_geol@yahoo.com.br

2 - Departamento de Recurso Minerais, Instituto de Ciências Exatas e da Terra, Universidade Federal de Mato Grosso, Cuiabá (MT), Brasil. E-mail: mapabarros@yahoo.com 
idade arqueana a paleoproterozóica, que serviu de anteparo aos arcos que foram acrescionados ao seu redor.

A área de estudo está localizada ao sul da Área Xingú-Iricoumé, nordeste de Mato Grosso, (Fig. 1). A porção sul da Área Xingú-Iricoumé (Área Xingú) é constituída por rochas plutônicas e vulcânicas paleoproteorozóicas. As rochas graníticas descritas por outros autores foram englobados nas seguintes unidades: 1) Suíte Intrusiva Parauari, 2) Suíte Creporizão, 3) Suíte Intrusiva Velho Guilherme, 4) Suíte Intrusiva Maloquinha, 5) Granito São Jorge Velho, 6) Granito São Jorge Jovem, 7) Suíte Intrusiva Vila Rica e 8) Suíte Intrusiva Rio Dourado. Associamse a essa granitogênese rochas vulcânicas de composição predominantemente félsica. Estas rochas magmáticas são cobertas por sedimentos de bacia mesoproterozóica formalmente incluídas na Formação Gorotire.

Os plutons graníticos mais antigos do sul da Área Xingú-Iricoumé, localizados no Pará, foram denominados como Suíte Intrusiva Parauari de idade U-Pb 1921 土 69 Ma (Macambira 1992) e Suíte Creporizão de idade U-Pb e Pb-Pb 2000 a $1960 \mathrm{Ma}$ (Klein \& Vasquez 2000, Santos et al. 2000, Lamarão et al. 2002). Esses granitos de idade em torno de 1,96 são interpretados como pós-colisionais em relação à Orogenia Transamazônica (João et al. 1985).

Lamarão et al. (2002) dividiram o Grupo Iri- ri em duas seqüências: Vila Riozinho de idade 2000 a 1970 Ma e Moraes Almeida de idade $1890 \pm 6$ a $1875 \pm$ $4 \mathrm{Ma}$, definindo assim dois períodos diferentes de atividades ígneas na Província Aurífera Tapajós.

Na região sul da área Xingú-Iricoumé, a Suíte Intrusiva Velho Guilherme é constituída pelos maciços graníticos: Antônio Vicente com idade $1867 \pm 4$ Ma (Teixeira et al. 2002a), Velho Guilherme (1874 \pm $30 \mathrm{Ma}$, Lafon et al. 1995), Mocambo (1862 $\pm 32 \mathrm{Ma}$, Teixeira et al. 2002a), granitos da Suíte Intrusiva Maloquinha $1880 \pm 9$ Ma, Lamarão et al. 2005 e Benedita e Ubim/Sul. O pluton granítico São Jorge, foi dividido em duas intrusões distintas com base em dados geocronológicos e geoquímicos, conhecidos como Granito São Jorge Velho de idade $1981 \pm 2$ Ma e Granito São Jorge Jovem $1891 \pm 3$ Ma (Lamarão et al. 2002).

GEOLOGIA LOCAL O Complexo Granítico-Gnáissico-Anfibolítico compreende as rochas mais antigas da área estudada, englobando anfibolitos, gnaisses de composição monzogranítica, milonitos, biotita-granodioritos deformados, quartzitos tectônicos e ocorrências pontuais de formações ferríferas. Estas rochas ocorrem formando colinas e mais raramente edificando serras. A deformação das rochas do embasamento varia desde discreta foliação até zonas milonitizadas. As rochas do Complexo Graníti-

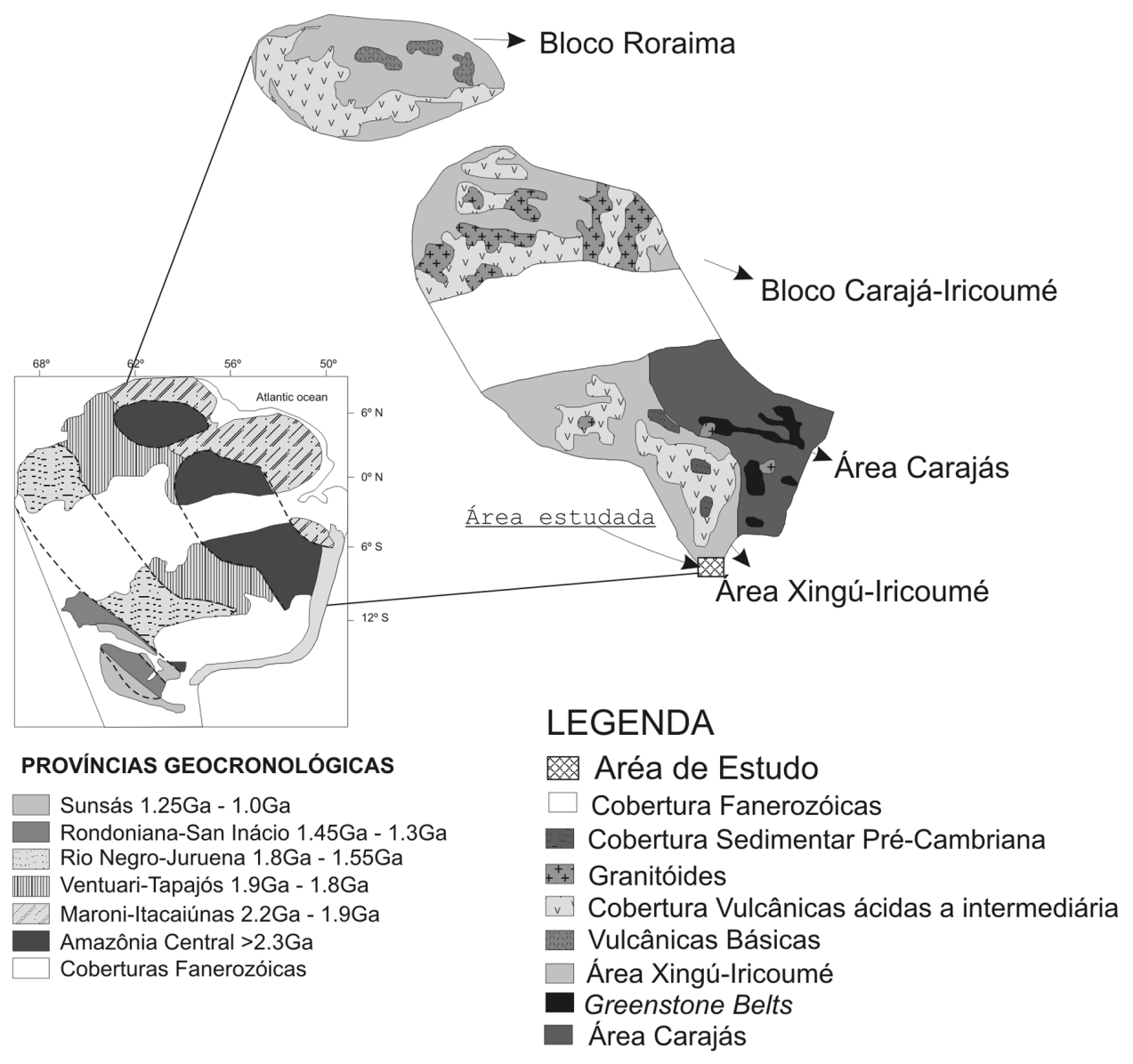

Figura 1 - Localização da área de estudo em relação às províncias geotectônicas do Cráton Amazônico destacando a Província Amazônia Central de Tassinari \& Macambira (1999). 
co-Gnáissico-Anfibolítico, em geral, possuem cores que variam de cinza-claro a cinza-escuro sendo comuns as texturas porfiroclásticas e os bandamentos gnáissicos. Os porfiroclastos de K-feldspato variam de 0,8 a $3 \mathrm{~cm}$ e a estrutura gnáissica é tipificada pela alternância de níveis claros compostos por quartzo e feldspatos e níveis escuros com biotita e anfibólio (Fig. 2A). Localmente estes gnaisses são cortados por diques pegmatíticos de direção SE/NW com espessura (em torno de $10 \mathrm{~cm}$ ), constituídos por quartzo e K-feldspato.

A Suíte Intrusiva Santa Inês é constituída por rochas que variam composicionalmente de hornblendito a hornblenda-gabro, possui coloração verde a verdeacinzentada, textura porfirítica a equigranular média a grossa. Este corpo apresenta localmente feições características de processos de cristalização fracionada tais como acamamentos crípticos e rítmicos (Fig. 2B) e evidências de um metassomatismo potássico marcado por $\mathrm{K}$-feldspato margeando cristais de hornblenda. (Pinho et al 2004b) havia denominado estas rochas de complexo estratiforme Santa Inez. Neste trabalho, as autoras propõem a utilização do termo suíte, por não terem encontrado até o momento variação litológica suficiente para manter a terminologia de complexo estratiforme.

Os granitos da Suíte Intrusiva Vila Rica estão bem expostos variando de biotita-monzogranito a biotita-sienogranito e raros quartzo sienitos. São rochas de coloração cinza-clara, por vezes rósea-acinzentada, granulação fina a média com foliação incipiente a mo- derada. Padilha et al. (inédito), obteve pelo método U-Pb em zircão idade de $1970 \pm 11$ Ma para uma amostra desta suíte e valores de $\mathrm{T}_{\mathrm{DM}}$ entre $-4,8$ a -9,9 Ga com $\epsilon_{\mathrm{Nd}}$ entre $-4,8$ a $-9,9$.

O Grupo Iriri na área constitui-se predominantemente de rochas de composição félsica (Pinho et al. 2004a). Os dados de campo e petrográficos permitiram identificar dois depósitos vulcânicos: um de caráter efusivo e outro piroclástico. Os depósitos efusivos são constituídos de riolitos maciços a porfiríticos em sua maioria, com coloração cinza a cinza-avermelhada. Os tipos porfiríticos mostram fenocristais de feldspato potássico e quartzo e matriz micropoiquilítica exibindo foliação de fluxo. A rocha foi afetada por hidrotermalismo que atingiu principalmente a matriz, com processos de sericitização. Os depósitos piroclásticos são constituídos por rochas de caráter explosivo: ignimbritos, tufos de queda e brechas. Os ignimbritos possuem tonalidade rósea, exibem ao microscópio textura eutaxítica, fiammes e intercalam-se com depósitos de queda. As brechas, por sua vez, mostram coloração cinza a cinza-rósea, com fragmentos líticos, de composição polimodal, que variam de milimétricos à decimétricos (Fig. 2C).

A Suíte Intrusiva Rio Dourado distribui-se na forma de blocos e matacões edificando serras e colinas suaves intrudindo a Suíte Intrusiva Vila Rica e o complexo granítico-gnáissico-anfibolítico. Uma feição comum no campo é a proximidade geográfica de ro-
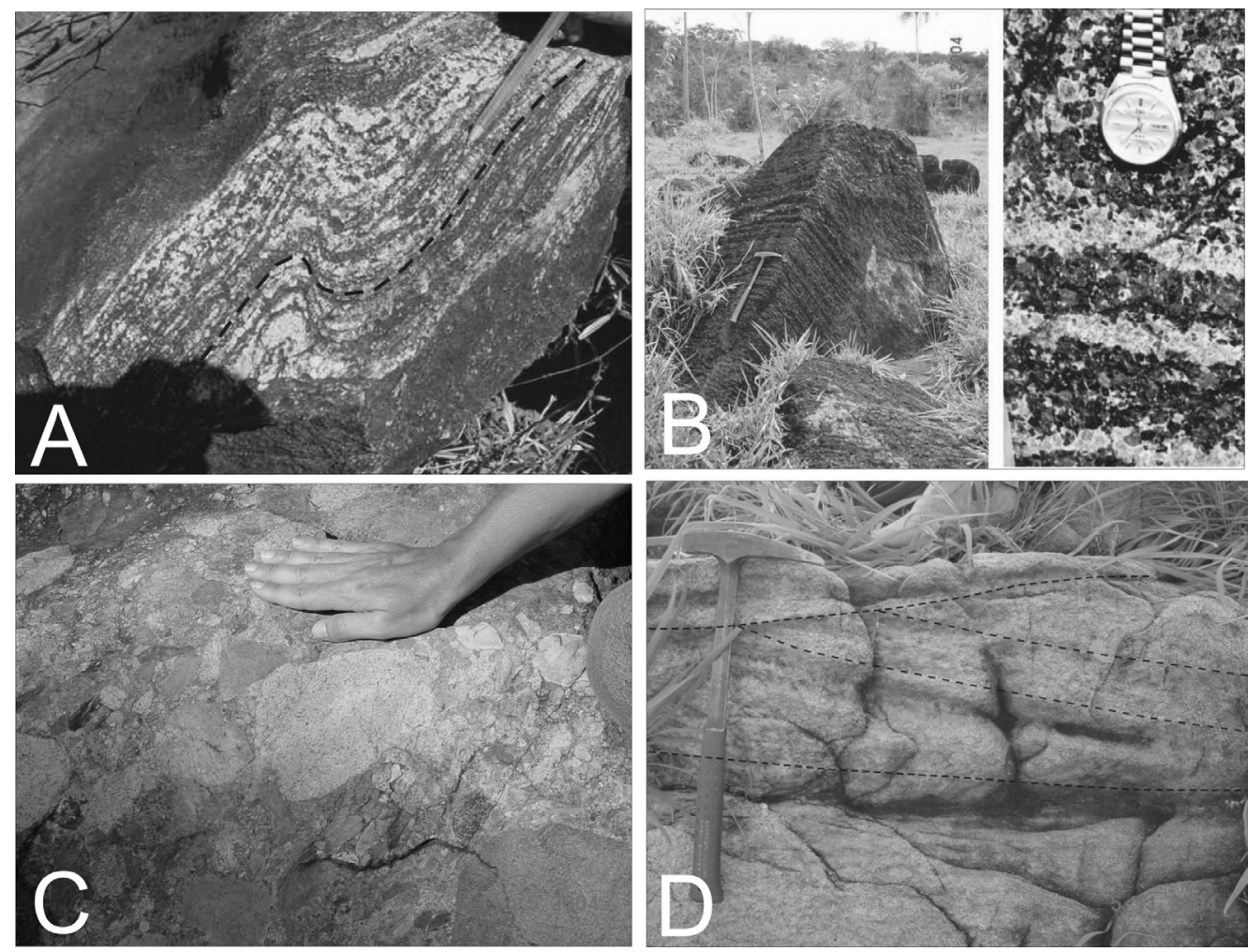

Figura 2 - Aspectos de campo das diferentes unidades estudadas. (A) deformação do Complexo-Granítico-Gnáissico; (B) acamamento rítmico da Suite Intrusiva Santa Inês; (C) brechas piroclásticas do Grupo Iriri; (D) Estratificações cruzadas da Formação Gorotire. 
chas pertencentes à Suíte Intrusiva Rio Dourado e as rochas vulcânicas ácidas do Grupo Iriri. O contato entre ambas é, em geral, difuso, sugerindo que as rochas da suíte intrusiva Rio Dourado e as do Grupo Iriri são co-magmáticas. Estas evidências de campo são comprovadas pela similaridade das idades obtidas: $1.890 \pm$ 11 Ma para a Suíte Intrusiva Rio Dourado (Barros et al. 2005) e $1.880 \pm 43$ Ma para as vulcânicas do Grupo Iriri (Pinho et al. 2004a). Os granitos da Suíte Intrusiva Rio Dourado são isotrópicos, com granulação média a grossa, tonalidade rósea-avermelhada a rósea-esbranquiçada, apresentando estrutura rapakivi em um dos maciços. Comumente a Suíte Intrusiva Rio Dourado apresenta grande quantidade de xenólitos composições variadas, sendo observados fragmentos da Suíte Intrusiva Vila Rica, do Complexo-Gnáissico-Anfibolítico e da Suíte Intrusiva Santa Inês. Bolsões pegmatíticos e injeções aplíticas de espessura milimétrica a centimétrica também são feições importantes na Suíte Intrusiva Rio Dourado.

A Formação Gorotire ocorre assentada, discordantemente, sobre as rochas do Grupo Iriri e da Suíte Intrusiva Rio Dourado. Esta formação constitui-se de um pacote sedimentar com basculamento para SW, com duas direções de fraturas bem marcadas e intensa silicificação. Na área de pesquisa, foram identificados arenitos que variam de fino a grosso, com coloração brancaacinzentada a branca-rosada, e estratificação cruzada acanalada de médio a grande porte (Fig. 2D).

\section{PETROGRAFIA DOS CORPOS GRANITICOS ESTUDADOS}

Suíte Intrusiva Vila Rica Apesar das variações composicionais (Fig. 3), os granitos da Suíte Intrusiva Vila Rica guardam semelhanças texturais entre si: possuem textura hipidiomórfica a alotriomórfica, inequigranular fina a média (variando em torno de 0,3 a $3,5 \mathrm{~mm}$ ) sendo comuns intercrescimentos mirmequíticos e quartzo recristalizado que indicam re-equilíbrio mineralógico como resposta às mudanças de condições de pressão e temperatura.

O biotita-monzogranito apresenta tonalidade variando de cinza-clara a rósea-acinzentada e constitui-se de plagioclásio (31-46\%), quartzo (18-30\%), feldspato potássico (15-24\%) e biotita (5-6\%). O quartzo ocorre como cristais anédricos fraturados formando subgrãos (Fig. 4A), com extinção ondulante, ou como conjunto de cristais em mosaico resultantes de recristalização. Os cristais de quartzo geram localmente agregados microcristalinos margeando os feldspatos e preenchendo microfraturas. $\mathrm{O}$ plagioclásio $\left(\mathrm{An}_{20-30}\right)$ ocorre na forma prismática equidimensional subédrica a anédrica. Alguns cristais apresentam aspecto turvo devido a saussuritização (Fig. 4B). O microclínio, reconhecido pela macla xadrez, ocorre em cristais subédricos a anédricos, possui inclusões de biotita e minerais acessórios. Alguns cristais estão fraturados e as microfraturas são preenchidas por quartzo, feldspatos e clorita microcristalina. Parte dos cristais de microclínio estão sericitizados e alguns apresentam bordas constituídas de plagioclásio (textura rapakivi) ou são margeados por quartzo

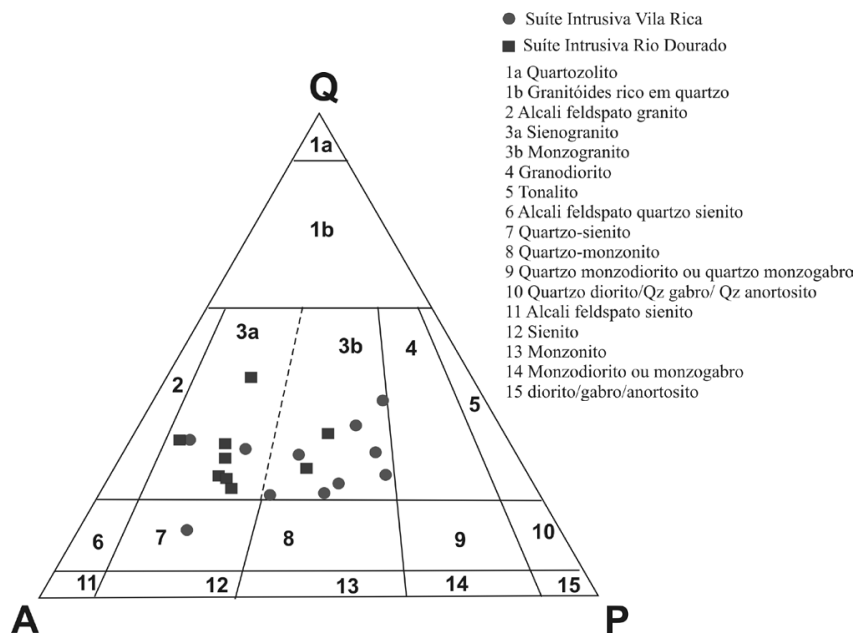

Figura 3 - Classificação petrográfica de amostras representativas das Suites Intrusivas Vila Rica e Rio Dourado no diagrama QAP de Streckeisen (1979).

microcristalino (Fig. 4C). Os intercrescimentos pertíticos em filmes são comuns no microclínio. A Biotita ocorre na cor marrom e pleocroísmo marrom-escuro a marrom-pálido, em forma de palhetas subédricas, apresentando localmente encurvamento das clivagens, indicando deformação incipiente. Quando alteradas transformam-se em clorita. Apatita e zircão ocorrem como inclusões na biotita. A clorita (3\%) de cor verde ocorre como produto de alteração da biotita e mostra hábito fibroso e cor de interferência cinza azulada. Onde o processo de alteração não foi completo, a clorita ocorre interdigitada com a biotita. Como minerais secundários ainda ocorrem sericita (2\%) e epidoto (1-2\%). Apatita, titanita, allanita, zircão e opacos (pirita, magnetita e ilmenita) são os minerais acessórios deste litotipo que variam de euédricos a subédricos, perfazendo $2 \%$ da composição modal da rocha.

O biotita-sienogranito possui cor cinza-clara e constitui-se de feldspato potássico (47-56\%), quartzo (30-17\%), plagioclásio (21-27\%) e biotita (em torno de $6 \%$ ). O microclínio ocorre em maior abundância, aparece em hábito prismático e apresenta inclusões poiquilíticas de plagioclásio. Às vezes, mostra a borda margeada por quartzo recristalizado. A pertita, em filmes é abundante (Fig. 4D). O quartzo é anédrico, faz contato irregular com outros cristais, tem extinção ondulante e localmente alguns cristais exibem evidências de cataclase. O plagioclásio possui hábito prismático, está saussuritizado, sendo que o grau de alteração impossibilita calcular o teor de anortita. A biotita ocorre em palhetas preenchendo interstícios entre os cristais. Como minerais secundários ocorrem sericita e clorita (em torno de $2 \%$ ) e como minerais acessórios (em torno de 1 a $2 \%$ ) foram identificados opacos (magnetita e ilmenita), apatita e zircão que variam de euédricos a anédricos.

Suíte Intrusiva Rio Dourado A análise de composição modal dos granitos da Suíte Intrusiva Rio Dourado 

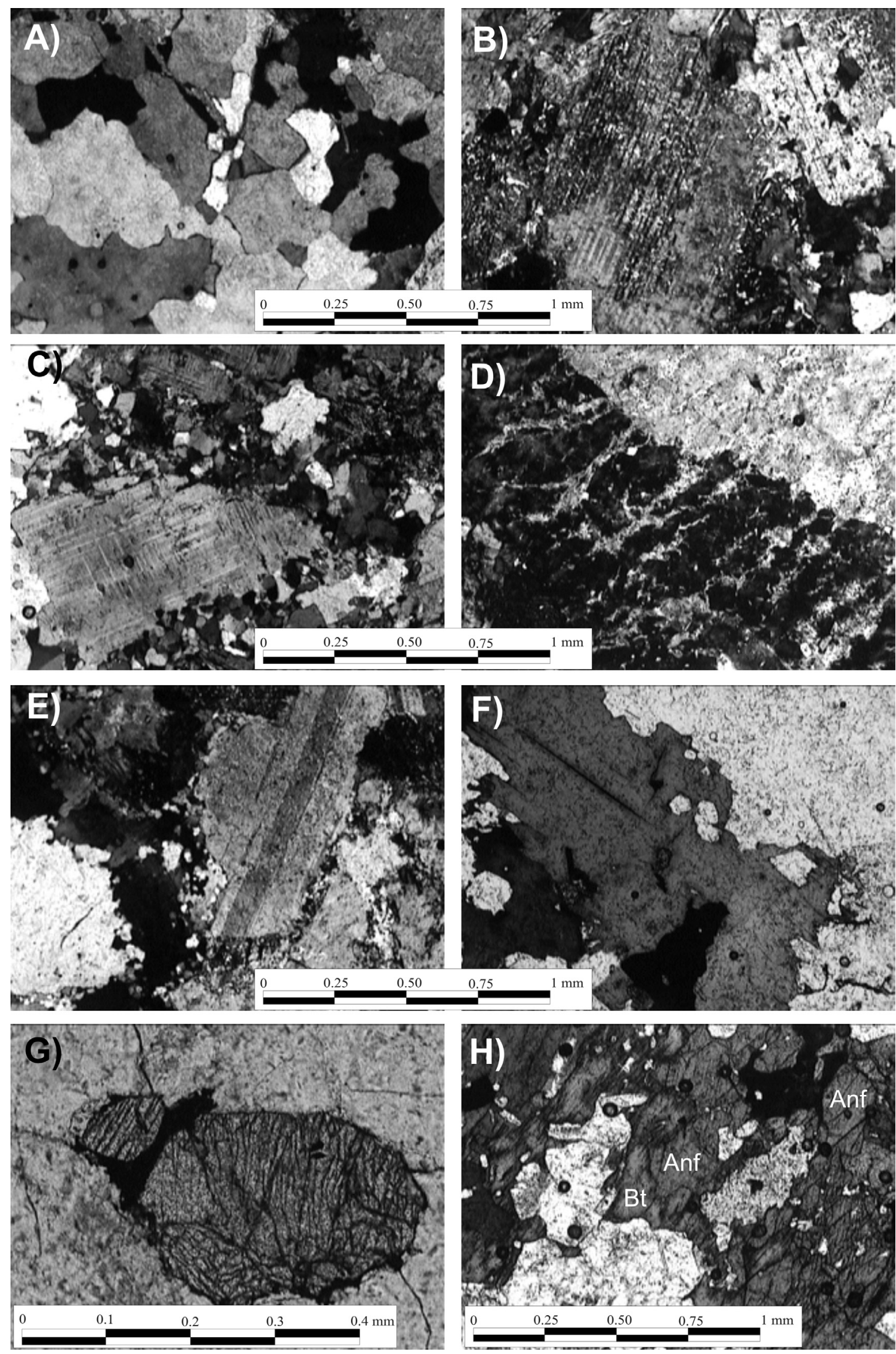

Figura 4 - Texturas microscópicas das Suites Intrusiva Vila Rica (SIVR) e Rio Dourado (SIRD). (A) Quartzo fraturado formando subgrãos (SIVL); (B) Plagioclásio saussuritizado (SIVL); (C) Microclínio exibindo bordas de dissolução com aspecto de corrosão ou recristalização sendo margeadas as vezes por plagioclásio elou quartzo microcristalino (SIVL); (D) Pertita em filmes originadas por processos de ex-solução (SIVL); (E) Borda de dissolução (SIRD); (F) Biotita em forma de palheta anédrica (SIRD); (G) cristal de titanita (SIRD); (H) Anfibólio associado com biotita (SIRD). 
indicou composições predominantes sienogranítica e subordinadamente monzogranítica (Fig. 3). Três variedades petrográficas foram identificadas: biotita-sienogranito, biotita-sienogranito com anfibólio e monzogranito. A textura destas rochas é hipidiomórfica a alotriomórfica, inequigranular fina a média $(0,4$ a 4 mm), onde são comuns feições poiquíliticas e recristalização de quartzo.

O biotita-sienogranito é constituído por feldspato potássico (microclínio pertítico) (50-54\%), quartzo (25-31\%), plagioclásio (16-18\%) e biotita (em torno de 5 a $6 \%$ ), sendo comuns intercrescimentos mirmequíticos. Borda de dissolução e recristalização aparece em todos os minerais da rocha exceto na biotita (Fig. 4E), sendo estas bordas bem nítidas em alguns cristais de quartzo. $\mathrm{O}$ microclínio é predominantemente pertítico sendo que bandas sódicas ocorrem na forma de filmes e 'drops'. Variam desde cristais subédricos a anédricos, com eventuais inclusões de quartzo. O quartzo é anédrico e exibe extinção ondulante. O plagioclásio está em sua totalidade saussuritizado, o que não permitiu identificar o teor de anortita pelo método Michel-Levi. A alteração dá origem a micas brancas associadas com epidoto. A biotita possui cor marrom com pleocroísmo para marrom-amarelado, em forma de palhetas subédricas, ocupando espaços intersticiais entre os cristais ou como cristal isolado contendo inclusões poiquíliticas de apatita e zircão (Fig. 4F). A clorita (2-3\%) aparece como produto de alteração da biotita, é verde-clara com cor de interferência azulada e chega a formar agregados associados com os minerais opacos. Neste litotipo, ocorrem como minerais acessórios (cerca de 1-2\%) apatita, titanita, opacos (magnetita e ilmenita) e zircão. A titanita muitas vezes ocorre com cor marrom forte e relevo acentuado (Fig. 4G), bastante fraturada e muitas vezes associada a alanita e rutilo.

O Monzogranito é constituído por plagioclásio (39\%), feldspato potássico (29\%) e quartzo (26\%), com textura alotriomórfica, inequigranular e raros intercrescimentos mirmequíticos. O plagioclásio varia de subédrico a anédrico, a alteração avançada (saussuritização) dificultou a estimativa do teor de anortita. O quartzo exibe extinção ondulante, com cristais anédricos, e ocorre em subgrãos indicando processo de deformação incipiente localizada. O microclínio identificado pela macla xadrez bem preservada, exibe intercrescimento pertítico. As bandas sódicas das pertitas em filmes associadas com pertitas de substituição são abundantes. Estas texturas indicam que a suíte Intrusiva Rio Dourado é dominantemente do tipo subsolvus, mas que, no entanto, por ser afetada por um processo metassomático tardio chega a apresentar processos de substituição de um feldspato por outro. O microclínio mostra borda de dissolução preenchida com plagioclásio microcristalino caracterizando a textura rapakivi. A biotita (3\%) ocorre na forma de palhetas preenchendo os interstícios ou como aglomerados de cristais associados com clorita. Como minerais secundários (1\%) ocorrem a clorita (peninita), epidoto e sericita-muscovita. Os minerais acessórios (1 a 2\%) presentes são apatita, fluorita, allanita, titanita, zircão e opacos (pirita, magnetita e ilmenita).
O Biotita-sienogranito com anfibólio têm textura xenomórfica, de granulação média, constituindo-se mineralogicamente por feldspato alcalino (51\%), quartzo $(29 \%)$, plagioclásio $(7 \%)$, biotita $(6 \%)$ e anfibólio $(3 \%)$ e opacos $(2 \%)$. Todos os minerais nesta rocha ocorrem como cristais anédricos sendo que o ortoclásio é pertítico e mostra bordas corroídas circundadas por plagioclásio microcristalino. Quase todos os cristais de ortoclásio estão parcialmente sericitizados e possuem inclusões poiquilíticas de quartzo, plagioclásio e minerais opacos. O quartzo têm extinção ondulante e está fraturado. O plagioclásio $\left(\mathrm{An}_{{ }_{12-20}}\right)$ possui geminação segunda a lei da albita, evidências de zonação e foi afetado por alteração hidrotermal, estando parcialmente saussuritizado. A biotita marrom ocorre em forma de palhetas subédricas e, às vezes, anédricas, sendo que alguns cristais estão alterados para clorita. O anfibólio possui cor verde e forma prismática subédrica (Fig. $4 \mathrm{H})$. Análise em microscópio eletrônico de varredura (MEV), realizada na UFPA, sugere que este anfibólio seja hastingsita (Fig. 4F). Como minerais acessórios $(2 \%)$ ocorrem apatita, titanita, allanita, zircão, fluorita e opacos (pirita, ilmenita e magnetita).

A presença de hastingsita na Suíte Intrusiva Rio Dourado, o caráter dominante subsolvus indicado pelos intercrescimentos pertíticos e a presença constante da textura rapakivi são fortes argumentos para considerar a Suíte Intrusiva Rio Dourado como parte de um magmatismo Rapakivi do tipo A.

\section{GEOQUIMICA}

Métodos Analíticos Treze amostras dos granitos estudados foram selecionadas na petrografia, foram enviadas para análises químicas, sendo que sete análises foram realizadas no ACTLABS (Activation Laboratories Ltd, Canadá) e seis no laboratório Lakefield - Geosol Geologia e Sondagem Ltda. No ACTLABS para elementos maiores utilizou-se ICP-ES (Inductivel Coupled Plasma - Emission Spectrometry) com abertura por fusão com Tetraborato de Lítio, enquanto que para os elementos terras raras e traços utilizou-se ICP/MS (Inductivel Coupled Plasma-Mass Spectrometry). O F foi analisado pelo método SIE (Specific Ion Electrod).

No laboratório Lakefield - Geosol Geologia e Sondagem Ltda, os elementos maiores foram analisados por Fluorescência de Raios-X com abertura por fusão com Tetraborato de Lítio, enquanto que para os elementos $\mathrm{Ba}, \mathrm{Rb}, \mathrm{Sr}, \mathrm{Th}, \mathrm{Zr}$, Nb, Y, utilizou-se pastilhas de pó prensado e leituras por Fluorescência de Raios-X. Os elementos $\mathrm{Pb}, \mathrm{Cu}, \mathrm{Ni}, \mathrm{Mo}, \mathrm{Zn}$ por método de absorção atômica com abertura por digestão multiácida e o F pelo método Eletrodo de Ion Especifico. Os elementos terras raras foram analisados por ICP/MS.

$\mathrm{B} M \mathrm{G}=\mathrm{b}$ i o t it a-monzogranito; $\mathrm{MG}=$ monzogranito; $\mathrm{QS}=$ quartzo-sienito; $\mathrm{BSG}=$ Biotitasienogranito; $\mathrm{ABSG}=$ anfibólio-biotita-sienogranito; nd=não detectado. • Amostras analisadas no laboratório ACTLABS; - amostras analisadas no laboratório Lakefield - Geosol Geologia e Sondagem Ltda. 
Suíte Intrusiva Vila Rica A Suíte Intrusiva Vila Rica possui valores de $\mathrm{SiO}_{2}$ entre 70,3 e $74,7 \%$, razão $\mathrm{K}_{2} \mathrm{O} /$ $\mathrm{Na}_{2} \mathrm{O}(1,0-2,7)$, teores de $\mathrm{Al}_{2} \mathrm{O}_{3}$ entre 12,9 a $15,3 \%$, $\mathrm{CaO}$ entre 1 a $1,78 \%$ e $\mathrm{Fe}_{2} \mathrm{O}_{3}$ entre 0,53 a $2,9 \%$. Os teores elevados de $\mathrm{SiO}_{2}$ são aqui interpretados como resultantes de um enriquecimento durante o processo de deformação que provoca uma silicificação nas rochas da Suíte Intrusiva Vila Rica. Este aumento de $\mathrm{SiO}_{2}$ é acompanho pelo empobrecimento em Ba que varia de 814 a 5365 ppm e aumento de $\operatorname{Sr}(266$ a 569 ppm). Os valores de $\mathrm{Zr}$ (148-489 ppm), Rb (113-220 ppm), Y (9,3-38 ppm) e F (150-490 ppm), são moderados e de Ga (13-22 ppm), Zn (22-39 ppm), Ni (4,8-37 ppm) e $\mathrm{Cu}(0,8-26 \mathrm{ppm})$ são normais para este tipo de granitóide. $\mathrm{TiO}_{2}$ mostra correlação negativa com $\mathrm{SiO}_{2}$ provavelmente devido a precipitação de ilmenita durante o avanço da cristalização magmática. Com relação aos elementos traços apenas o $\mathrm{Sr}$ mostra correlação positiva com $\mathrm{SiO}_{2}$ (Fig. 5) enquanto os demais elementos apresentam dispersão. Zr mostra correlação negativa com $\mathrm{Sr}$ e positiva com Rb e Zn. (Fig. 6). Os demais elementos apresentam dispersão, o que demonstra que a Suíte Intrusiva Vila Rica foi afetada por uma fase hidrotermal tardia relacionada ao evento deformacional.

As amostras estudadas da Suíte Intrusiva Vila Rica possuem razão $\mathrm{FeO}_{t} /\left(\mathrm{FeO}_{\mathrm{t}}+\mathrm{MgO}\right)$ entre 0,4 e 0,8 classificando-as como cálcio-alcalina (Frost et al., 2001).
Em relação ao índice de saturação em alumina a Suíte Intrusiva Vila Rica é fracamente peraluminosa (Fig. 7), sendo os valores de ISA $\left[\mathrm{Al}_{2} \mathrm{O}_{3} /\left(\mathrm{CaO}+\mathrm{Na}_{2} \mathrm{O}+\mathrm{K}_{2} \mathrm{O}\right)\right]$ entre 1,2 e 1,5 evidenciado no diagrama de Maniar \& Picolli (1989). Assinatura cálcio-alcalina de alto-K pode ser observada no diagrama $\mathrm{SiO}_{2}$ versus $\mathrm{K}_{2} \mathrm{O}$ (Fig. 8) proposto por (Rickwood 1989).

Os granitos desta suíte mostram um padrão de distribuição dos Elementos Terras Raras (ETR) marcado pelo enriquecimento de terras raras leves sobre pesados. Os ETR leves mostram um acentuado fracionamento, contrastando com a disposição mais suave dos ETR pesados (Fig. 8). A razão ( $\mathrm{La} / \mathrm{Lu})_{\mathrm{N}}$ alcança valores entre 93,75 e 20 indicando um alto grau de fracionamento dos ETR. Entre os ETRL nota-se um fracionamento interno alto, expresso pela razão $(\mathrm{La} / \mathrm{Sm})_{N}$ cujos valores variam de 5 a 11,75. Em relação ao fracionamento interno dos ETRP, os valores são moderados com razões $(\mathrm{Gd} / \mathrm{Lu})_{\mathrm{N}}$ que variam 1,3 e 1,6. A análise do diagrama multielementar normalizado pelos valores do ORG (Granitos de Cadeias Oceânicas) são caracterizados por anomalia negativa de $\mathrm{Nb}$ e Ta (Fig. 8B), anomalias comuns em ambientes tectônicos influenciados por processos de subducção. Teores de $\mathrm{Rb}$ versus $\mathrm{Y}+\mathrm{Nb}$ projetam os granitos desta suíte no campo de granitos pós-colisionais (Fig. 9)
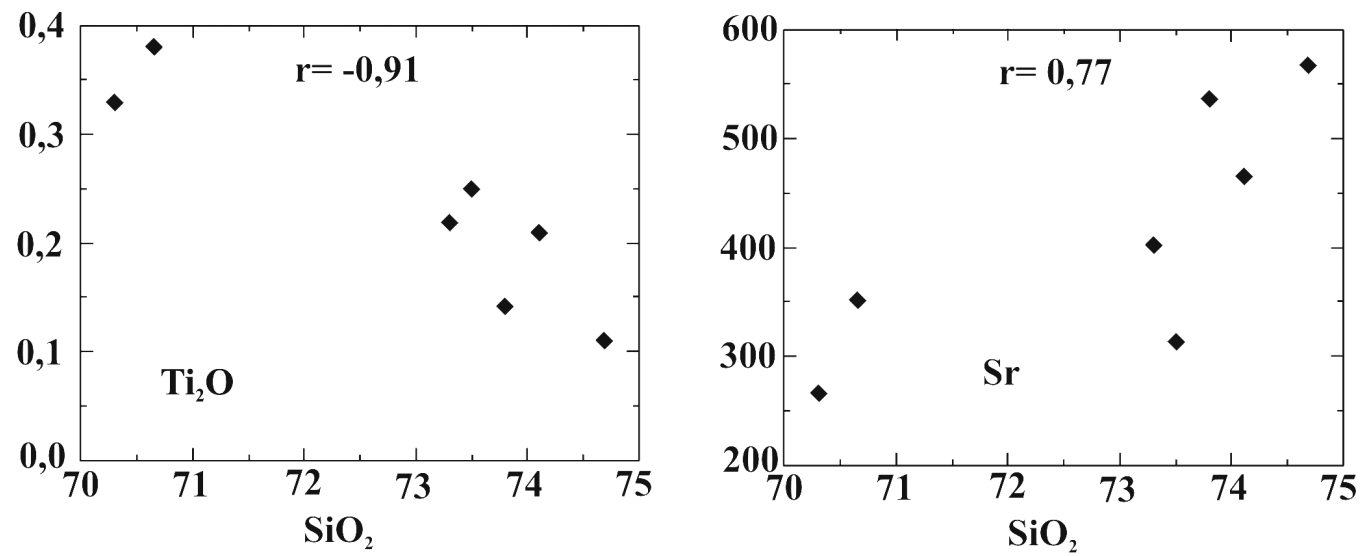

Figura 5 - Diagramas $\mathrm{SiO}_{2}$ versus $\mathrm{TiO}_{2}$ e $\mathrm{Sr}$ dos granitos da Suite Intrusiva Vila Rica.
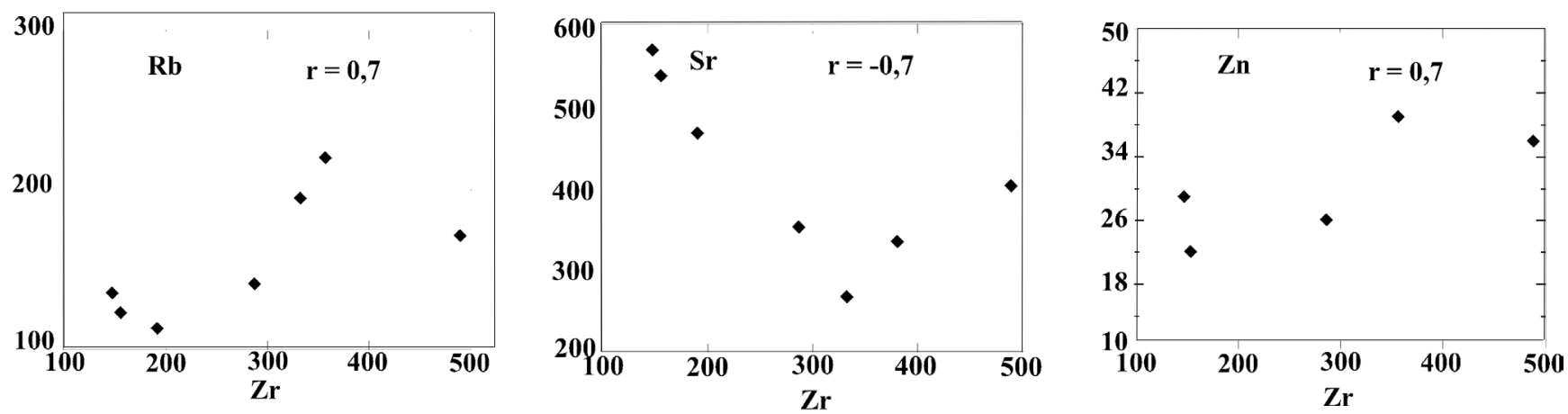

Figura 6 - Diagramas Zr versus $\mathrm{Sr}$, Rb e Zn da Suite Intrusiva Vila Rica. 
A)

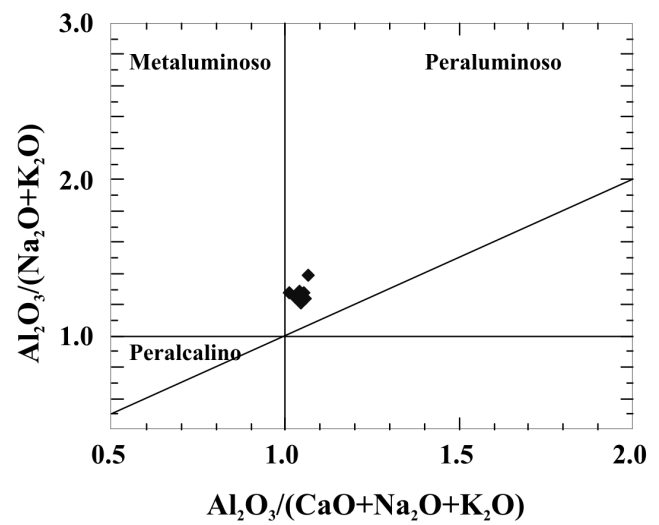

B)

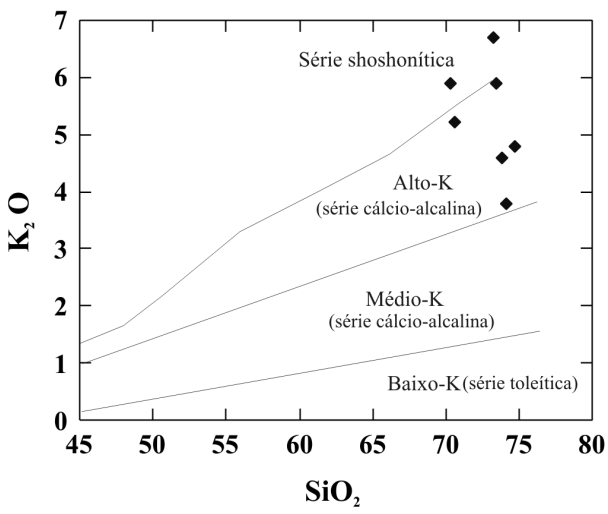

Figura 7 - Suite Intrusiva Vila Rica. (A) Diagrama A/CNK versus A/NK (Maniar \& Piccoli 1989) mostrando o caráter peraluminoso dos granitos da Suite Intrusiva Vila Rica; (B) Diagrama de correlação entre $\mathrm{SiO}_{2}$ versus $\mathrm{K}_{2} \mathrm{O}$, mostrando o grau de alcalinidade e teor de potássio (Rickwood 1989).
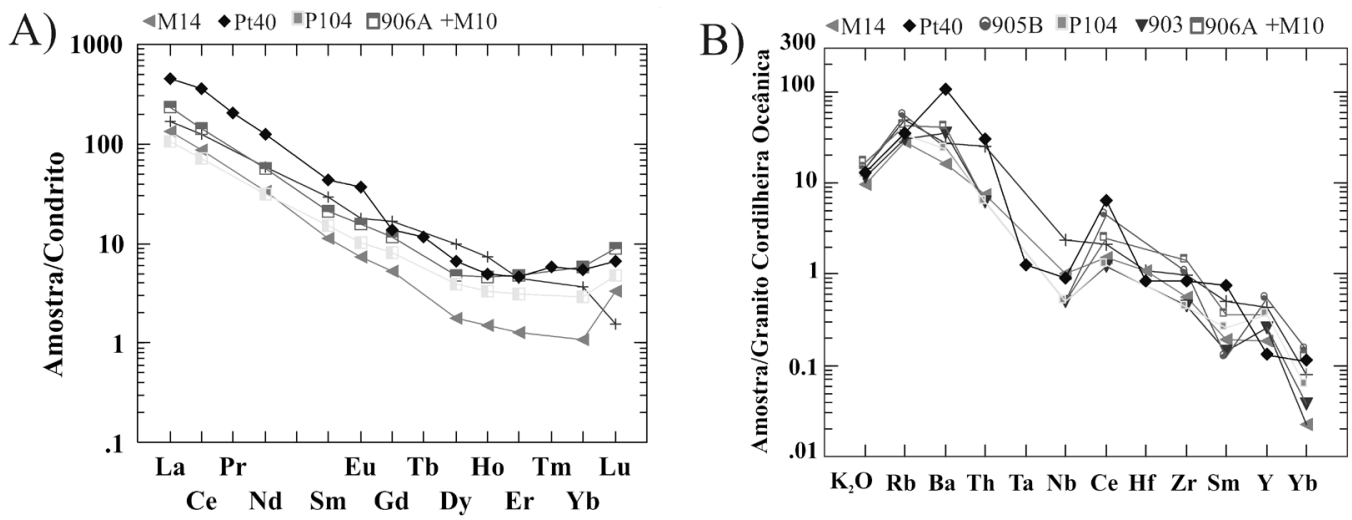

Figura 8 - Suite Intrusiva Vila Rica. (A) Padrão de elementos terras raras dos granitos da Suite Intrusiva Vila Rica normalizado pelos condritos; (B) Diagrama multielementar para os granitos da Suite Intrusiva Vila Rica normalizado pelos Granitos de Cadeias Oceânicas.

Suíte Intrusiva Rio Dourado Os resultados dos elementos maiores, traços e terras raras para seis amostras desta unidade são mostrados na tabela 1 . Os valores de $\mathrm{SiO}_{2}$ da Suíte Intrusiva Rio Dourado variam entre 69,05 e $73,52 \%$, sendo estes teores mais baixos do que aqueles apresentados pela Suíte Intrusiva Vila Rica. Teores de $\mathrm{Fe}_{2} \mathrm{O}_{3}$ entre $2,02-4,73 \%$ são moderadamente elevados e são compatíveis com um granito rico em minerais ferro-magnesianos e com aspectos petrográficos similares a granitos de afinidade rapakivi. Da mesma forma os teores mais elevados de Y (14,7-67,5 ppm) e F (260-1040 ppm) são esperados neste tipo de magmatismo bem como os baixos valores de $\mathrm{Ni}(2,7-7,1 \mathrm{ppm})$ e $\mathrm{Cu}(3,2-9,4$ ppm.

As amostras estudadas da Suíte Intrusiva Rio Dourado variam de metaluminosa a peraluminosas de acordo com o diagrama $\mathrm{Al}_{2} \mathrm{O}_{3} /\left(\mathrm{CaO}+\mathrm{Na}_{2} \mathrm{O}+\mathrm{K}_{2} \mathrm{O}\right)$ versus $\mathrm{Al}_{2} \mathrm{O}_{3} /\left(\mathrm{Na}_{2} \mathrm{O}+\mathrm{K}_{2} \mathrm{O}\right)$ de Maniar \& Picolli (1989,

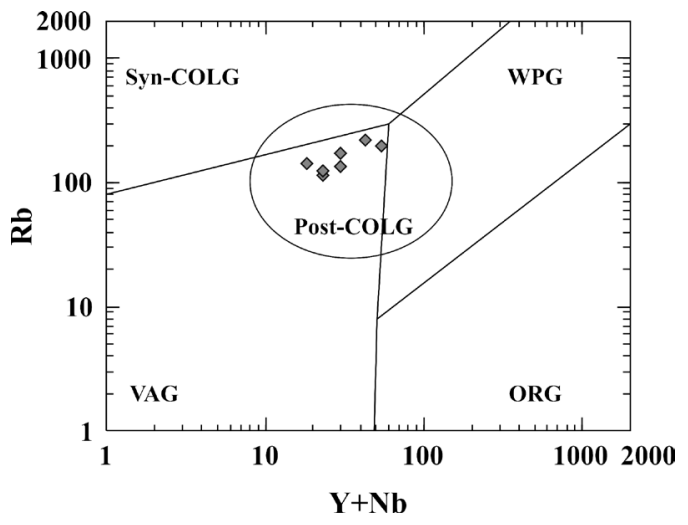

Figura 9 - Diagrama Rb versus $\mathrm{Y}+\mathrm{Nb}(\mathrm{Pe}$ arce et al. 1984, Pearce 1996), para as rochas das Suites Intrusivas Vila Rica. 
Petrologia e geoquímica das suites intrusivas Vila Rica e Rio Dourado - Província Amazônia Central, borda sudeste do Cráton Amazônico (MT)

Tabela 1 - Dados de Elementos Maiores e Traços para sete amostras da Suite Intrusiva Vila Rica e seis amostras da Suite Intrusiva Rio Dourado. Óxidos em \% em peso e elementos traços e terras raras em ppm.

\begin{tabular}{|c|c|c|c|c|c|c|c|c|c|c|c|c|c|}
\hline \multirow[b]{2}{*}{$\mathrm{N}^{\circ}$ de Amostras } & \multicolumn{7}{|c|}{ Suíte Intrusiva Vila Rica } & \multicolumn{6}{|c|}{ Suíte Intrusiva Rio Dourado } \\
\hline & M10 & M14 & 903 & P104 & $905 \mathrm{~B}$ & Pt40 & $906 \mathrm{~A}$ & V4 & $905 \mathrm{~A}$ & R14 & $\mathrm{P} 24$ & R27B & V1 \\
\hline legenda & - & - & - & - & - & $\bullet$ & - & $\bullet$ & $\bullet$ & $\bullet$ & $\bullet$ & $\bullet$ & $\bullet$ \\
\hline Fácies & BMG & BMG & BMG & BMG & BMG & BMG & QS & BSG & BSG & MG & ABSG & BSG & ABSG \\
\hline $\mathrm{SiO}_{2}$ & 70,3 & 74,1 & 73,8 & 74,7 & 73,5 & 70,65 & 73,3 & 70,05 & 71,19 & 71,59 & 69,05 & 73,52 & 71,19 \\
\hline $\mathrm{Al}_{2} \mathrm{O}_{3}$ & 15,3 & 12,9 & 14,3 & 14,2 & 13,9 & 14,81 & 13,6 & 12,76 & 13,93 & 14,23 & 15,19 & 13,25 & 13,18 \\
\hline $\mathrm{Fe}_{2} \mathrm{O}_{3}$ & 2,9 & 2,8 & 0,53 & $<0,01$ & 0,53 & 2,7 & 0,54 & 2,04 & 3,48 & 2,02 & 3,12 & 2,77 & 4,73 \\
\hline $\mathrm{MgO}$ & 0,50 & 0,85 & 0,2 & 0,23 & 0,36 & 0,46 & 0,53 & 0,16 & 0,47 & 0,40 & 0,34 & 0,20 & 0,38 \\
\hline $\mathrm{CaO}$ & 1,4 & 1,3 & 1,6 & 1,1 & 1,3 & 1,78 & 1 & 0,72 & 1,49 & 1,22 & 1,53 & 0,74 & 1,29 \\
\hline $\mathrm{Na}_{2} \mathrm{O}$ & 3,4 & 3,6 & 3,8 & 3,8 & 2,9 & 3,06 & 2,4 & 3,07 & 2,79 & 2,76 & 3,85 & 3,58 & 3,37 \\
\hline $\mathrm{K} 2 \mathrm{O}$ & 5,9 & 3,8 & 4,6 & 4,8 & 5,9 & 5,21 & 6,7 & 5,67 & 5,73 & 5,88 & 5,85 & 5,18 & 5,04 \\
\hline $\mathrm{TiO}_{2}$ & 0,33 & 0,21 & 0,14 & 0,11 & 0,25 & 0,38 & 0,22 & 0,26 & 0,30 & 0,25 & 0,36 & 0,20 & 0,39 \\
\hline $\mathrm{P}_{2} \mathrm{O}_{5}$ & 0,079 & 0,73 & 0,052 & 0,034 & 0,066 & 0,07 & 0,076 & 0,04 & 0,09 & 0,06 & 0,07 & 0,03 & 0,08 \\
\hline $\mathrm{MnO}$ & 0,04 & 0,06 & 0,04 & 0,04 & 0,04 & 0,04 & 0,04 & 0,04 & 0,04 & 0,03 & 0,06 & 0,05 & 0,08 \\
\hline LOI & 0,02 & 0,09 & 0,74 & 0,3 & 0,52 & 0,02 & 0,39 & 1,1 & 0,3 & 1,4 & 0,4 & 0,3 & 0,1 \\
\hline Mo & 5 & 5 & $<5$ & $<5$ & $<5$ & 0,9 & $<5$ & 0,8 & 0,3 & 0,9 & 1,6 & 1,3 & 2,2 \\
\hline $\mathrm{Cu}$ & 0,8 & 13 & 9 & 13 & 15 & 6,1 & 26 & 3,2 & 6,8 & 4,7 & 7,1 & 9,4 & 8,3 \\
\hline $\mathrm{Pb}$ & 30 & 41 & 28 & 32 & 28 & 8,8 & 30 & 8,5 & 11,2 & 20,2 & 9,6 & 11,5 & 12,7 \\
\hline $\mathrm{Zn}$ & nd & nd & 22 & 29 & 39 & 26 & 36 & 21 & 36 & 25 & 28 & 27 & 33 \\
\hline $\mathrm{Ni}$ & 5,9 & 8,6 & 22 & 11 & 37 & 4,8 & 19 & 6,6 & 5,8 & 7,1 & 2,7 & 3,3 & 3,6 \\
\hline $\mathrm{Au}$ & nd & nd & nd & nd & nd & 0,7 & nd & 2 & 1,4 & 4,5 & 12,3 & 3,8 & 19 \\
\hline $\mathrm{Ba}$ & 1335 & 814 & 1749 & 1162 & 1213 & 5365,1 & 2023 & 774,4 & 1367,3 & 974,8 & 1441 & 346,2 & 1036,7 \\
\hline Co & nd & nd & nd & nd & nd & 2,6 & nd & 1,4 & 3,6 & 86,4 & 2,9 & 1,8 & 3,5 \\
\hline $\mathrm{Cs}$ & nd & nd & nd & nd & nd & 3,4 & nd & 4,1 & 1,7 & 5,2 & 3,3 & 2,7 & 3,1 \\
\hline $\mathrm{Ga}$ & 22 & 21 & 15 & 20 & 17 & 15,4 & 13 & 17,1 & 16,4 & 17,1 & 18,4 & 16,7 & 15,5 \\
\hline Hf & 10 & 10 & nd & nd & nd & 7,6 & nd & 6,7 & 7,7 & 6,6 & 7,8 & 4,9 & 8,3 \\
\hline $\mathrm{Nb}$ & 24 & 10 & $<5$ & $<5$ & $<5$ & 9,1 & $<5$ & 15,8 & 9,6 & 15,1 & 14,9 & 13,8 & 14,6 \\
\hline $\mathrm{Rb}$ & 195 & 113 & 123 & 135 & 220 & 141,3 & 171 & 237,5 & 193,4 & 256,5 & 166 & 211,4 & 185,4 \\
\hline $\mathrm{Sr}$ & 266 & 466 & 537 & 569 & 315 & 351,5 & 404 & 86 & 217,3 & 196,7 & 223 & 82,8 & 136,9 \\
\hline $\mathrm{Ta}$ & 10 & 10 & nd & nd & nd & 0,9 & nd & 1,4 & 0,5 & 2,3 & 0,9 & 0,9 & 0,9 \\
\hline Th & 20 & 6 & $<5$ & $<5$ & $<5$ & 24,2 & $<5$ & 16,9 & 31,1 & 42 & 16,4 & 35,5 & 14,3 \\
\hline $\mathrm{U}$ & 10 & 10 & nd & nd & nd & 3,3 & nd & 4,6 & 1,8 & 7,2 & 4,6 & 6,3 & 3,3 \\
\hline $\mathrm{V}$ & 11 & 10 & $<10$ & $<10$ & 13 & 19 & 23 & 6 & 28 & 24 & 18 & 9 & 16 \\
\hline W & nd & nd & nd & nd & nd & 0,6 & nd & 1,2 & 0,4 & 858,8 & 1,2 & 2,8 & 1,5 \\
\hline $\mathrm{Zr}$ & 332 & 192 & 156 & 148 & 357 & 288,0 & 489 & 198 & 269,7 & 183,4 & 294,9 & 173,4 & 287,4 \\
\hline $\mathrm{Y}$ & 30 & 13 & 18 & 25 & 38 & 9,3 & 25 & 67,5 & 14,7 & 40,6 & 30 & 34,5 & 31,2 \\
\hline $\mathrm{F}$ & 400 & 460 & 150 & 380 & 490 & 160 & 330 & 870 & 490 & 260 & 720 & 830 & 1040 \\
\hline $\mathrm{La}$ & 39,900 & 32,050 & 26,3 & 25,1 & 78,2 & 106,6 & 55,7 & 41,3 & 75,1 & 65,9 & 43,2 & 47,9 & 31,3 \\
\hline $\mathrm{Ce}$ & 75,170 & 53,430 & 42,1 & 43,9 & 157 & 221,4 & 86,3 & 99,1 & 180 & 149,7 & 88,3 & 92,8 & 66,3 \\
\hline $\operatorname{Pr}$ & nd & nd & nd & nd & nd & 19,77 & nd & 11,15 & 17,21 & 14,94 & 10,60 & 10,71 & 8,03 \\
\hline $\mathrm{Nd}$ & 27,110 & 15,680 & 11,8 & 14,6 & 53,5 & 58,9 & 26,2 & 45,7 & 57,9 & 49,8 & 37,9 & 37 & 30,7 \\
\hline $\mathrm{Sm}$ & 4,494 & 1,722 & 1,3 & 2,3 & 1,1 & 6,7 & 3,2 & 11,4 & 7,7 & 8,2 & 6,8 & 6,13 & 6,21 \\
\hline $\mathrm{Eu}$ & 1,018 & 0,423 & 0,81 & 0,59 & 0,95 & 2,16 & 0,91 & 0,65 & 0,88 & 0,92 & 1,32 & 0,64 & 0,90 \\
\hline $\mathrm{Gd}$ & 3,397 & 1,083 & 0,94 & 1,67 & 5,23 & 2,81 & 2,4 & 11,69 & 4,69 & 5,73 & 4,83 & 4,53 & 4,82 \\
\hline $\mathrm{Tb}$ & nd & nd & nd & nd & nd & 0,43 & nd & 2,28 & 0,64 & 1,14 & 0,9 & 0,84 & 0,91 \\
\hline Dy & 2,486 & 0,444 & 0,33 & 0,98 & 2,45 & 1,71 & 1,21 & 11,55 & 2,65 & 5,33 & 4,75 & 4,73 & 4,88 \\
\hline Но & 0,420 & 0,085 & 0,07 & 0,19 & 0,46 & 0,28 & 0,26 & 2,44 & 0,44 & 1,22 & 0,97 & 1,01 & 1,03 \\
\hline $\mathrm{Er}$ & 0,745 & 0,212 & 0,18 & 0,52 & 1,27 & 0,76 & 0,78 & 6,69 & 1,4 & 3,39 & 2,64 & 3,16 & 3 \\
\hline $\mathrm{Tm}$ & nd & nd & nd & nd & nd & 0,15 & nd & 0,89 & 0,19 & 0,52 & 0,4 & 0,51 & 0,47 \\
\hline $\mathrm{Yb}$ & 0,629 & 0,182 & 0,3 & 0,5 & 1,2 & 0,92 & 1 & 4,5 & 1,1 & 3,04 & 2,5 & 2,96 & 2,71 \\
\hline $\mathrm{Lu}$ & 0,039 & 0,083 & 0,11 & 0,12 & 0,05 & 0,17 & 0,23 & 0,71 & 0,20 & 0,52 & 0,38 & 0,49 & 0,43 \\
\hline$\sum$ ERT & 155,40 & 105,39 & 84,24 & 90,47 & 302,68 & 422,76 & 178,19 & 250,05 & 350,10 & 310,35 & 205,49 & 213,41 & 161,69 \\
\hline $\mathrm{FeO} /(\mathrm{FeO}+\mathrm{MgO})$ & 0,84 & 0,74 & 0,70 & 0,03 & 0,56 & 0,83 & 0,47 & 0,92 & 0,87 & 0,82 & 0,89 & 0,92 & 0,92 \\
\hline $\mathrm{Na}_{2} \mathrm{O}+\mathrm{K}_{2} \mathrm{O}$ & 9,3 & 7,4 & 8,4 & 8,6 & 8,8 & 7,2 & 9,1 & 8,7 & 8,5 & 8,64 & 9,7 & 8,7 & 8,4 \\
\hline $\mathrm{K}_{2} \mathrm{O} / \mathrm{Na}_{2} \mathrm{O}$ & 1,7 & 1,0 & 1,2 & 1,2 & 2,0 & 1,7 & 2,7 & 1,8 & 2,0 & 2,1 & 1,5 & 1,4 & 1,5 \\
\hline $\mathrm{Ga} /\left(\mathrm{Al}_{2} \mathrm{O}_{3} * 0,52\right)$ & 2,76 & 3,13 & 2,01 & 2,70 & 2,35 & 1,99 & 1,83 & 2,57 & 2,26 & 2,3 & 2,29 & 2,4 & 2,26 \\
\hline $\mathrm{Ce}+\mathrm{Y}+\mathrm{Nb}+\mathrm{Zr}$ & 461,17 & 268,43 & 221,1 & 221,9 & 557 & 527,8 & 605,3 & 380,4 & 474 & 388,8 & 428,1 & 314,5 & 399,5 \\
\hline $\mathrm{Th} / \mathrm{U}$ & 0,6 & 2 & nd & nd & nd & 7,33 & nd & 3,67 & 17,27 & 5,83 & 3,56 & 5,63 & 4,33 \\
\hline $\mathrm{Th} / \mathrm{Ta}$ & 0,6 & 2 & nd & nd & nd & 26,88 & nd & 12,07 & 62,2 & 18,26 & 18,22 & 34,44 & 15,88 \\
\hline$(\mathrm{La} / \mathrm{Lu})_{\mathrm{N}}$ & 40 & 93,75 & nd & 20 & nd & 58,75 & 23,33 & 6 & 37,5 & 13,86 & 12,85 & 10 & 6,66 \\
\hline$(\mathrm{La} / \mathrm{Sm})_{\mathrm{N}}$ & 10 & 5 & nd & 6,2 & nd & 11,75 & 10,5 & 2,57 & 7,5 & 5,6 & 3,91 & 5 & 3 \\
\hline$(\mathrm{Gd} / \mathrm{Lu})_{\mathrm{N}}$ & 1,6 & 11,25 & nd & 1,6 & nd & 1,5 & 1,3 & 1,66 & 2,52 & 1,38 & 1,44 & 1,01 & 1,26 \\
\hline
\end{tabular}


Fig. 10A). As razões $\mathrm{FeO}_{\mathrm{t}} /\left(\mathrm{FeO}_{\mathrm{t}}+\mathrm{MgO}\right)$ variam de 0,8 a 0,9 , as quais são aceitas para granitos -alcalinos, tipo-A (Frost et al, 2001). No diagrama de Whalen et al. (1987) usando $\left(\mathrm{Na}_{2} \mathrm{O}+\mathrm{K}_{2} \mathrm{O}\right) / \mathrm{CaO}$ versus $\mathrm{Zr}+\mathrm{Y}+\mathrm{Ce}+\mathrm{Nb}$, as amostras da Suíte Intrusiva Rio Dourado plotam no campo de granitos tipo-A (Fig. 10 B).

A Suíte Intrusiva Rio Dourado possui padrões de elementos terras raras caracterizados pelo enriquecimento de leves sobre pesados e forte anomalia negativa de $\mathrm{Eu}$ (Fig. 11). A razão $(\mathrm{La} / \mathrm{Lu})_{\mathrm{N}}$ alcança valores entre $37,5 \mathrm{e}$ 6 indicando um fracionamento moderado dos Elementos Terras Raras leves em relação aos ETR pesados. Entre os ETR leves, nota-se um fracionamento interno moderado, expresso pelas razões de $(\mathrm{La} / \mathrm{Sm})_{\mathrm{N}}$, que variam de 7,5 a 2,57. Em relação ao fracionamento interno de ETR pesados, observam-se valores baixos da razão $(\mathrm{Gd} / \mathrm{Lu})_{\mathrm{N}}$,
Vila Rica possuem razão $\mathrm{FeO}_{\mathrm{t}} /\left(\mathrm{FeO}_{\mathrm{t}}+\mathrm{MgO}\right)$ entre $0,4 \mathrm{e}$ 0,8 e $\mathrm{K}_{2} \mathrm{O}$ acima de $3 \%$ caracterizando rochas cálcioalcalinas a alto-K. Com relação a alumina-saturação concentram-se no campo de rochas fracamente peraluminosas. A Suíte Intrusiva Vila Rica mostra padrão de elementos terras raras (ETR) com fracionamento de ETR leves sobre pesados, sem anomalia de Eu, evidenciando uma origem a partir de magmas fracionados onde minerais máficos ficaram na fase residual. $\mathrm{O}$ período de 2.0 a 1.8 Ga no Cráton amazônico é marcado pela acresção do arco Ventuari-Tapajós à Província Amazônia Central. A assinatura das rochas magmáticas originadas em ambientes de arco nessa província mostram valores de End positivos (Cordani \& Teixeira, 2007). Lamarão et al (2005), entretanto estudou granitos paleoproterozóicos no bloco Xingu-Iricoumé com
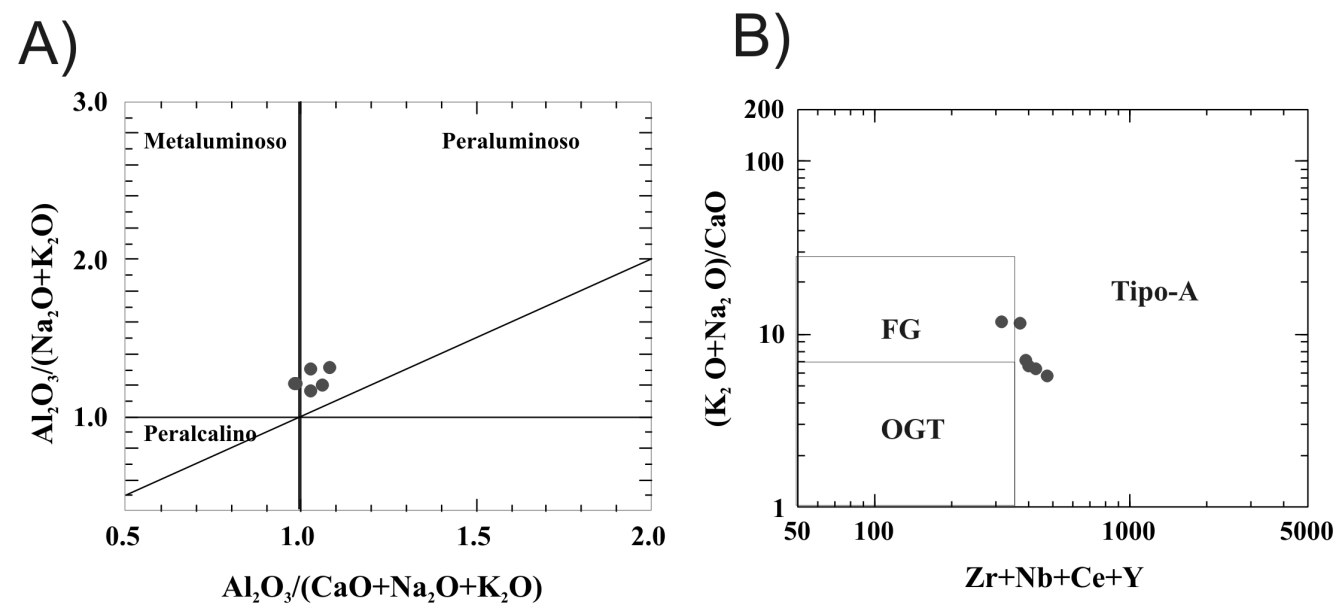

Figura 10 - Suite Intrusiva Rio Dourado. (A) Diagrama A/CNK versus A/NK (Maniar \& Piccoli 1989) mostrando o caráter metaluminoso a peraluminoso da Suíte Intrusiva Rio Dourado; (B) Diagrama $\mathrm{K}_{2} \mathrm{O}+\mathrm{Na}_{2} \mathrm{O} / \mathrm{CaO}$ versus $\mathrm{Zr}+\mathrm{Nb}+\mathrm{Ce}+\mathrm{Y}$ (Whalen et al. 1987). $F G$ : granitos félsicos fracionados; OFG: granitos tipo M I e $S$ não fracionados.

que variam de 2,52 a 1,01. A análise do diagrama multielementar normalizado pelos valores do ORG destaca anomalias negativas de $\mathrm{Ba}$, $\mathrm{Nb}$ e $\mathrm{Ta}$ (Fig. 12).

A Suíte Intrusiva Rio Dourado apresentam características geoquímicas com granitos tipo-A do subgrupo $\mathrm{A}_{2}$ (Fig. 13a e 13b), que segundo Eby (1992) inclui uma variedade de ambientes tectônicos. De acordo com os campos definidos por Pearce 1996, as amostras desta suíte plotam no campo de granitos pós-colisionais (Fig.14).

DISCUSSÕES E CONCLUSÕES Os estudos de campo, petrográficos e geoquímicos das suítes mencionadas permitiram concluir que a Suíte Intrusiva Vila Rica (1970 $\pm 9 \mathrm{Ma})$ é constituída por sienogranitos, monzogranitos e raros quartzo sienitos que apresentam deformação dúctil incipiente a moderada, dando origem a rochas com intensidade variável de deformação, desde levemente foliados até rochas com bandamentos gnáissicos. As amostras estudadas da Suíte Intrusiva

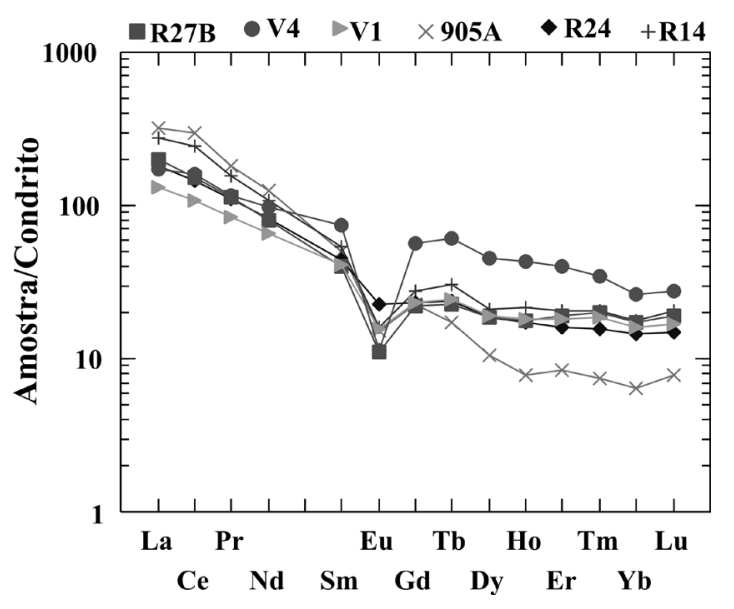

Figura 11 - Padrões de elementos terras raras da Suite Intrusiva Rio Dourado normalizado pelo condrito. 


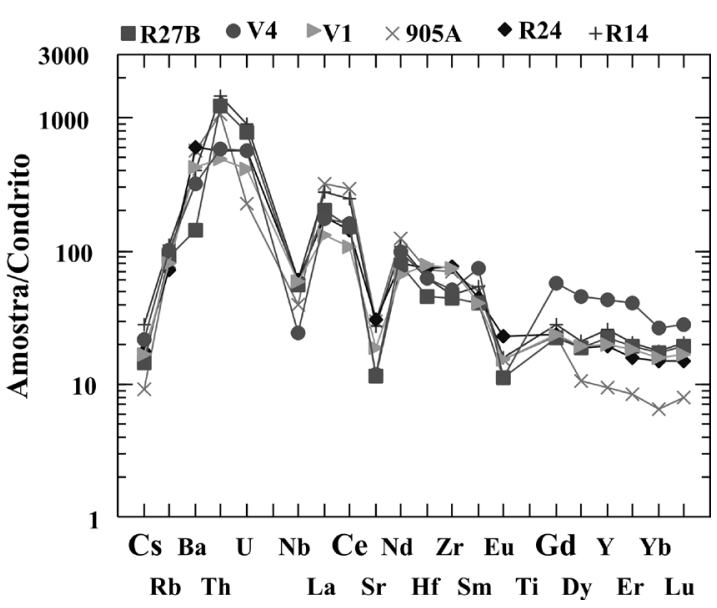

Figura 12 - Diagrama multielementar para a Suite Intrusiva Rio Dourado normalizado pelo Granito de Cordilheira Oceânica.

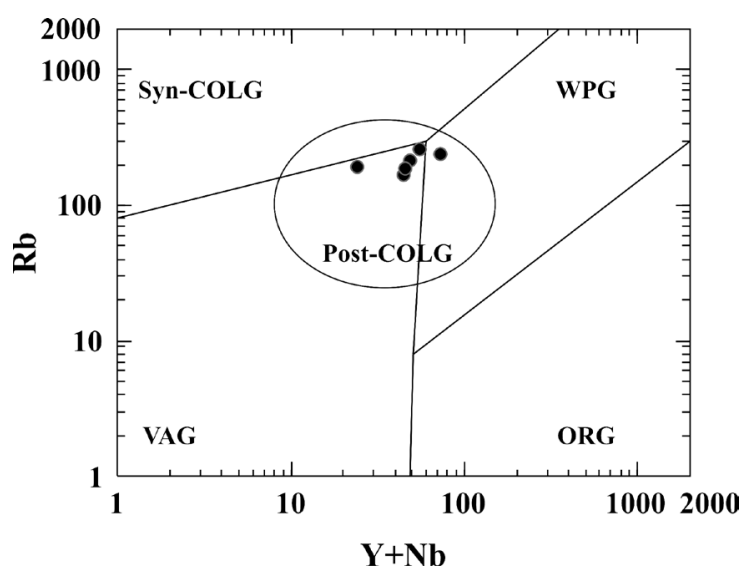

Figura 14 - Diagrama de Ambiente Tectônico proposto por Pearce (1996) aplicado para os granitos da Suite Intrusiva Rio Dourado.
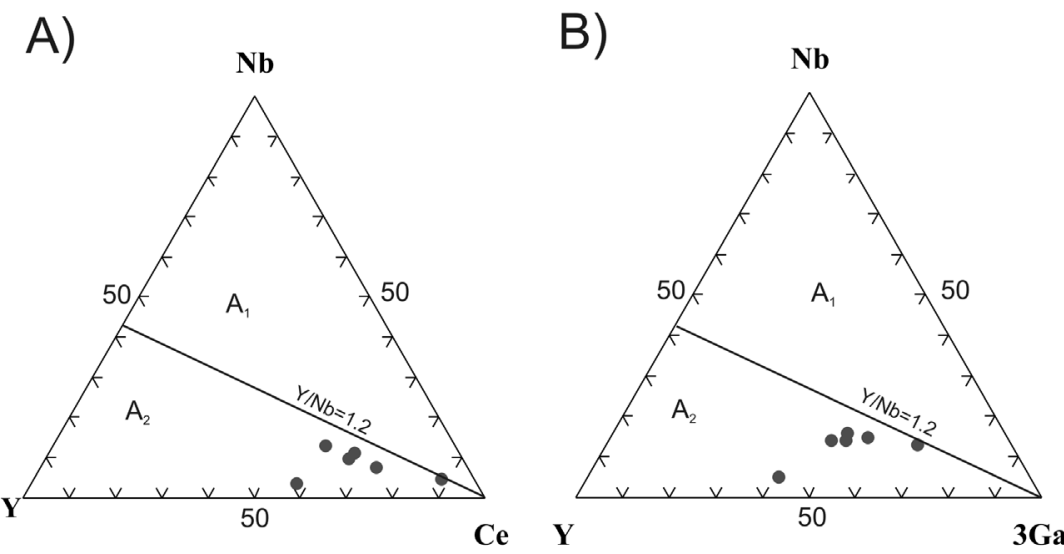

Figura 13 - Diagrama (A) Nb-Y-Ce e (B) Nb-Y-3Ga, mostrando a distribuição composicional da Suíte Intrusiva Rio Dourado (Eby 1992).

as mesmas características e idades da Suíte Intrusiva Vila Rica que apresentaram valores de 6 nd entre $-0,7$ e $-5,2$ e foram interpretados pelos autores como relacionados a uma subducção do tipo andina indicando fontes mantélicas juvenis contaminadas com crosta continental mais antiga. Neste trabalho propomos que a Suíte Intrusiva Vila Rica foi gerada durante uma pausa no período de acresção do arco Venturari-Tapajós, por processos extensionais pós-colisionais, originados de refusão de uma crosta arqueana. Isto pode ser considerado pela composição cálcico-alcalina rica em potássio, o caráter fracamente peraluminoso e os valores de End negativos $(-4,8$ a $-9,0)$ e idades $T_{D M}$ entre 2,6 a 2,9 Ga.

A Suíte Intrusiva Rio Dourado é dominantemente sienogranítica variando localmente para monzogranítica. Datação U-Pb em zircão mostrou idade de $1889 \pm 11 \mathrm{Ma}$ (Barros et al. 2005) sendo esta, a mesma idade das vulcânicas ácidas Iriri na região estudada

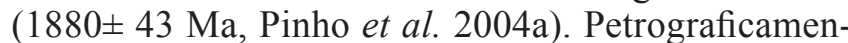
te, a Suíte Intrusiva Rio Dourado apresenta, feldspato alcalino pertítico e anfibólio sódico do tipo hastingsi- ta sugerindo uma afinidade com granitos alcalinos. A presença marcante de textura rapakivi, o caráter subsolvus destes granitos e o comportamento geoquímico permitem sugerir que estas rochas pertencem a um magmatismo do tipo A - Rapakivi. Esse caráter é reforçado pelo alto conteúdo de $\mathrm{Fe}_{2} \mathrm{O}_{3}(2,0-4,7 \%)$, razão de $\mathrm{FeO}_{/} /(\mathrm{FeO} / \mathrm{MgO})$ entre 0,8 e $0,9, \mathrm{Ce}+\mathrm{Y}+\mathrm{Nb}+\mathrm{Zr}$ (314,5-474) que são comuns em granitos tipo-A de afinidade rapakivi, bem como pelos teores de elementos maiores e traços que em diagramas descriminantes $\left(\mathrm{K}_{2} \mathrm{O}+\mathrm{Na}_{2} \mathrm{O}\right) / \mathrm{CaO}$ versus $\mathrm{Zr}+\mathrm{Y}+\mathrm{Ce}+\mathrm{Nb}$ plotam a Suíte Intrusiva Rio Dourado no campo de granito tipo-A. O padrão de elementos terras raras da Suíte Intrusiva Rio Dourado exibe moderado fracionamento de leves sobre pesados e anomalia negativa de Eu, indicando que o plagioclásio participou do processo de fracionamento durante a evolução do líquido magmático. Estudos de campo e geoquímico sugerem como ambiente geotectônico para a Suíte Intrusiva Rio Dourado um ambiente extensional, pós-colisional, com características petrográficas e químicas similares aos granitos 
do tipo-A do subgrupo $\mathrm{A}_{2}$ de afinidade rapakivi. A Suíte Intrusiva Rio Dourado possui afinidade petrografica e geoquímica semelhantes a granitos de mesma idade, distribuídos na Província Amazônia Central, (Suíte Intrusiva Maloquinha, Água Boa, Moderna entre outros) sugerindo que estes se originaram de um mesmo evento magmático que atingiu toda província.

Agradecimentos As autoras agradecem a Capes pela concessão da bolsa de mestrado da primeira autora, ao programa de pós-graduação em geociências da UFMT e a Cia Matogrossense de Mineração pelo financiamento de parte da pesquisa e ao CNPq pela bolsa de pós-doutorado da segunda autora que possibilitou obter dados isotópicos no laboratório de Geocronologia da UNB. A segunda autora agradece a colega de departamento Maria Zélia Aguiar da UFMT pelas discussões, aos revisores anônimos da Revista Brasileira de Geologia pelas críticas e sugestões.

\section{Referências}

Barros M.A.S., Padilha R.A., Rubert R.R., Silva G.D., Pimentel M.M. 2005. Grupo Iriri e Granito Rio Dourado, magmatismo Paleoproterozóico do sul da Área XingúIricoumé - Nordeste de Mato Grosso. In: Simp. de Vulcanismo e Ambientes Associados, Cabo Frio-RJ, atas.

Cordani U.G. \& Teixeira W. 2007. Proterozoic accretionary belts in the Amazonian Craton. The Geological Society of America Memoir, 200:297-319.

Eby G.N 1992. Chemical subdivision of the A-type granitoids: petrogeneses and tectonic implications. Geology, 20:641-644.

Frost B.R, Barnes C.G, Collins W.J, Arculus R.J., Ellis D.J., Frost C.D. 2001. A Geochemical classification for granitic rocks. Journal of Petrology, 12(11):2033-2048.

João X.S., Santos C.A., Provost A. 1985. Magmatismo Adamelítico Água Branca (Folha Rio Mapuera - NW do Estado do Pará). In: Simpósio Geológico da Amazônia, 2, Belém, Anais, p.93-109.

Klein E.L. \& Vasquez M.L. 2000. Projeto especial Província Mineral do Tapajós. Geologia e recursos minerais da folha SB.21-Z-A-Vila Riozinho, Estado do Pará, escala 1:250.000. Nota Explicativa. CPRM - Serviço Geológico do Brasil, CD-Rom.

Lafon J.M., Rodrigues E., Macambira E.M.B., Pereira E.D. 1995. Magmatisme anarogénique du Protérozoique Inférieur dans la région de São Felix do Xingu-Tucumã (Amazonie Orientale, Brésil). Nouvelles données geochronologiques. C. R. Acad. Sci. Paris, 320:937-944.

Lamarão C.N., Dall'Agnol R., Lafon J.M., Lima E.F. 2002. Dois eventos vulcânicos paleoproterozóicos na Província Aurífera do Tapajós: novos dados isotópicos Sm-Nd e implicações para o Supergrupo Uatumã. In: SBG, Simpósio de Vulcanismo e Ambientes associados, Belém, Boletim de Resumos e Roteiro da Excursão, p.27.

Lamarão C.N., Dall'agnol R., Pimentel M.M. 2005. Nd Isotopic composition of Paleoproterozoic volcanic and granitoid rocks of Vila Riozinho: implications for the crustal evolution of the Tapajós Gold Province, Amazon Craton. Journal of South America Earth Sciences, 18:277-292.

Macambira M.J.B. 1992. Chronologie U-Pb, Rb-Sr, K-Ar et croissance de la croûte continentale dans l'Amazonie du sul-est; example de la région de Rio Maria, Province de Carajás. Tese Doutoramento, Universidade de Montpellier II, Montpellier, 212p.

Manier P.D. \& Piccoli P.M. (1989). Tectonic Discrimination of Granitoids. Geological Society of America Bulletin,
101:635-643.

Pearce J.A., Harris N.B.W., Tindle A.G. 1984. Trace element discrimination diagrams for the tectonic interpretation of granitic rocks. J. Petrol., 25(4):956-983.

Pearce J.A. 1996. Source and settings of granitic rocks. Episodes, 19(4):120-125.

Pinho M.A.S.B., Rubert R.R., Silva G.D., Chemale Jr. F., Dussin I.A., Costa E.C. 2004a. Dados Petrográficos, Geoquímicos e idades U-Pb da vulcânica félsica do Grupo Iriri na porção nordeste de Mato Grosso - Serra dos Magalhães. In: SBG/Núcleo MG, Congresso Brasileiro de Geologia, 42, Araxá, Anais, CD-Rom.

Pinho M.A.S.B., Rubert R.R., Silva G.D., Oliveira L.A. 2004b. Intrusão Santa Inês, uma Suíte Estratiforme constituida por piroxênio-hornblendito a hornblendagabro, localizada no sudeste do Cráton Amazônico. In: SBG/Núcleo MG, Congresso Brasileiro de Geologia, 42, Araxá, Anais, CD-Rom.

Rickwood P.C. 1989. Boundary lines within petrologic diagrams which use oxides of major and minor elements. Lithos, 22(4):247-264.

Santos J.O.S., Hartmann L.A., Gaudette, H.E., Groves D.I., Mcnaughton N.J., Fletcher I.R.A. 2000. New Understanding of the Provinces of the Amazon Cráton based on Integration of Field Mapping and U-Pb and Sm-Nd Geochronology. Gondwana Research, 3(4):453-488.

Streckeisen A.L. 1976. To each plutonic rock its proper name. Earth Sci. Rev, 12:1-13.

Tassinari C.C.G. \& Macambira M.J.B. 1999. Geochronological provinces of the Amazonian Cráton. Episodes, 22 (3):174-182.

Teixeira N.P., Bettencourt J.S., Moura C.A.V., Dall'Agnol R., Macambira M.J.B. 2002. Archean crustal sources for Paleoproterozoic tin-mineralized granites in the Carajás Province, SSE Pará, Brazil: $\mathrm{Pb}-\mathrm{Pb}$ geochronology and $\mathrm{Nd}$ isotope geochemistry. Precambrian Research, 119 (1-4):257-275.

Whalen J.B., Currie K.L., Chappell B.W. 1987. A-type granites: geochemical characteristics discrimination and petrogenesis. Contrib. Mineral. Petrol., 95:407-419.

Manuscrito ID 9446 Submetido em 03 de outubro de 2007 Aceito em 17 de dezembro de 2008 Sistema eletrônico de submissão 